\title{
Earth Choreographer: Remediating Obsolete Grounds of the Future
}

\author{
Anna Korneeva*, Irmak Turanli \\ School of Architecture, Syracuse University, Syracuse, USA \\ Email address: \\ akorneev@syr.edu (A. Korneeva), ituranli@syr.edu (I. Turanli) \\ ${ }^{*}$ Corresponding author
}

\section{To cite this article:}

Anna Korneeva, Irmak Turanli. Earth Choreographer: Remediating Obsolete Grounds of the Future. International Journal of Architecture, Arts and Applications. Vol. 7, No. 3, 2021, pp. x-x. doi: 10.11648/j.ijaaa.20210703.14

Received: May 22, 2021; Accepted: September 11, 2021; Published: September 14, 2021

\begin{abstract}
Earth Choreographer is a design methodology that focuses on choreographing, scoring, and de-territorializing the landscape of an obsolete oil field. The project introduced in this article, titled Earth Choreographer, explores the imperatives and opportunities in remediation and repurposing of obsolete industrial sites, aiming to continuously investigate the potential of the land and possible scenarios over decades - even when the intended life cycle of the industrial site is over. It presents a design process that recognizes the ruination of the ground and the landscape. By acknowledging the evolving technologies and ever-increasing preoccupation with natural resources, it answers the following questions: 1) What happens when a productive landscape is sought to be both partially preserved and recreated? 2) How to represent a ground plane that is being constantly reconfigured by machines with ever-changing boundaries of spaces for human and non-human occupy? And 3) what does a site that constantly erases and reconstructs itself look like? With several scenarios from 2025 to 2080, this project acts as a prototype for inhabiting obsolete landscapes by addressing climate change and depletion of resources. Its dynamic design methodology allows the site to constantly evolve and change over time based on the needs and interests of its occupiers.
\end{abstract}

Keywords: Oil Extraction, Obsolete Landscape, Remediation, Repurposing, Prototype, Rammed Earth

\section{Introduction}

Fossil fuels are the largest energy producers in the world, however $\mathrm{CO}_{2}$ emissions from oil extraction and burning petroleum constitute about a quarter of the global gas emission [1]. Annually, 12 billion tons of $\mathrm{CO}_{2}$ is emitted to the atmosphere as a result of oil extraction, with the United States being the largest contributor emitting around 2.5 billion tons of $\mathrm{CO}_{2}$ [1]. Although fossil fuel industries are the largest energy producers in the world, the dependency on these industries is expected to decrease because of the depletion of natural resources and their negative effects on climate change. As the activities on the industrial sites will come to an end, many sites will soon become obsolete [2]. With evolving technologies, more complex regulatory and environmental policies and ever-increasing preoccupation with natural resources, architects have been designing new lives for obsolete post-industrial sites.

\section{Earth Choreographer}

\subsection{The Obsolescence}

This project, Earth Choreographer, began with the investigation of those industrial sites that are used outside of their original purpose once they reach the end of the intended life cycle. To analyze and compare them, a catalog of obsolete industrial facility types was produced to show the new programs deployed at post-industrial sites. The catalog included water towers, gasometers, tunnels of underground coal mines, oil tanks, air raid shelters and more. Most of these sites were repurposed for recreation and pleasure purposes [3].

In addition to analyzing obsolete industrial types, reprogramming of obsolete extraction sites were also investigated to better understand their influence on the landscape, environment and adjacent communities. Tagebau Hambach, being the largest open-pit coal mine in Germany 
was one of the precedents examined. Since the beginning of its operation in 1978, the excavation went as deep as 299 meters (980 ft) below sea level, and also grew horizontally, leaving only $10 \%$ of the ancient Hambach forest alive. The coal mine is expected to become obsolete by 2040, with no extractable coal remaining [4]. In an attempt to recover the mine, the company who owned the mine has planted over 10 million trees and plans to turn the coal pit into a large lake [5]. This proposal has served as an opportunity for architects and designers to speculate on the future of the Hambach, where the main program and use was recreation as an attempt to turn it into a “'positive' landscape, not looking backwards, because 'looking backwards can be painful'" [4].

Another example of a repurposed industrial site is the former coal mine Zollverein in Essen, built in 1847, which was later redeveloped and redesigned by the architecture firm OMA without removing the existing machines to emphasize its historic and cultural identity [6]. The redevelopment of Zollverein mainly focused on leisure and pleasure of visitors, romanticizing the post-industrial look and failing to critically comment on the unsustainable past of the coal mine.

Such repurposing of these sites fail to embrace contemporary environmental issues and their static, nonflexible designs and programs are also bound to eventually become obsolete. Therefore, Earth Choreographer is focused on a dynamic design that is constantly in flux as opposed to previously seen static examples.

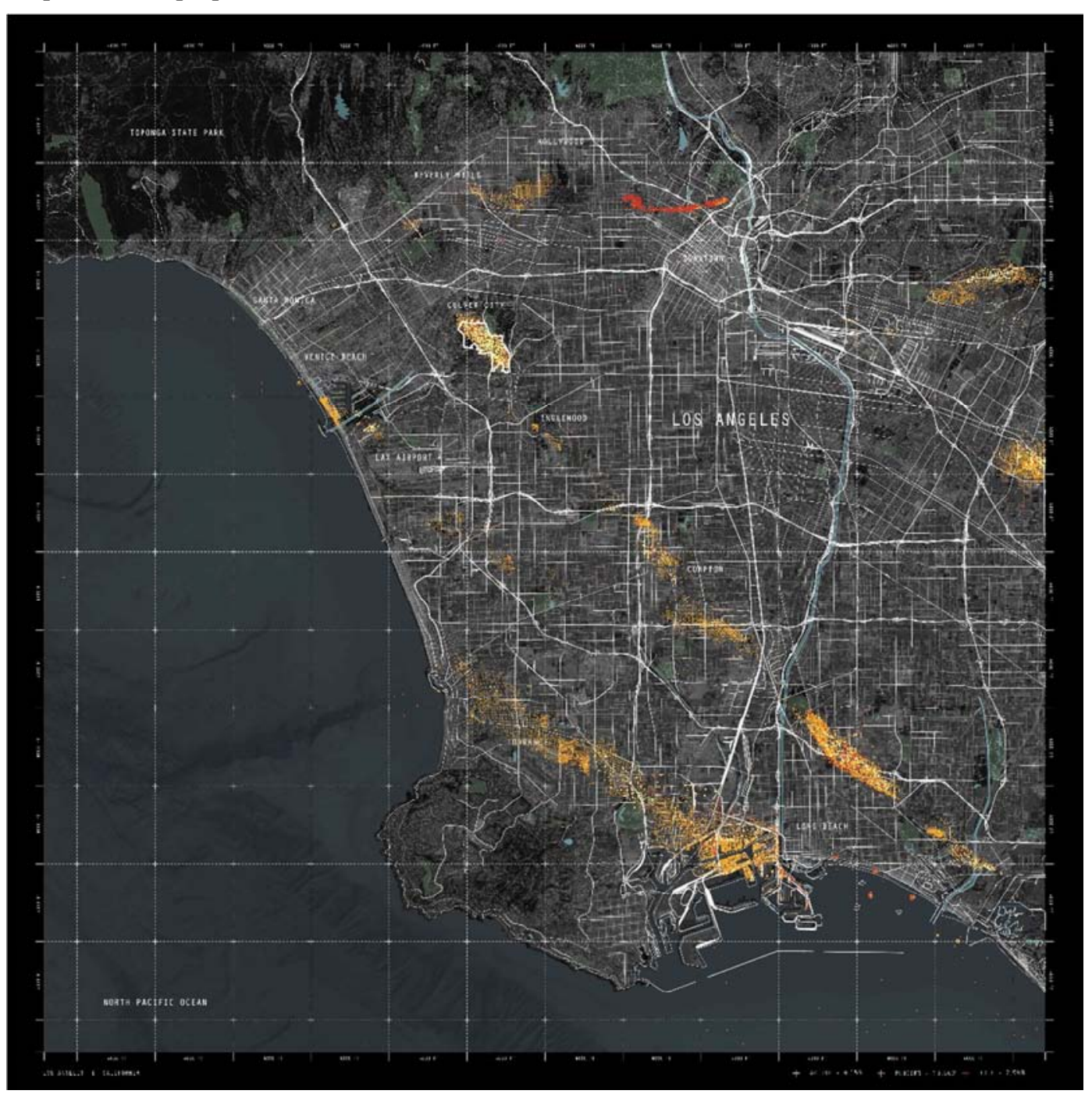

Figure 1. Distribution of Oil Wells in Los Angeles, California.

\subsection{The Location}

After investigating various obsolete precedents, Inglewood Oil Field, the largest contiguous urban oil field in the U.S. located in the center of Los Angeles, California (Figure 1), was selected. Discovered in 1924 and in continuous production ever since, it has produced almost 400 million barrels of oil. The oil field is visually entirely open to the public, and it was developed in the traditional manner of individual pump jacks on drilling pads. There are many homes, schools, and recreational parks adjacent to the oil field. Today, the oil field covers approximately 1,000 acres and there are a total of 1,601 wells, 696 of which are still active [7].

Being the largest urban oil field in the country and having 
more than a million people living within five miles of its boundaries, the site is a focal point of controversy. Of the people living in the surrounding area, $52 \%$ are Black, a much higher percentage than the countywide $8 \%$ [8]. People living around the site are far more likely to breathe air polluted by oil and gas operations, therefore burdening families with air pollution and poor health outcomes including lung disease, leukemia, lymphoma and lung cancer [9]. In April 2021, Inglewood Oil Field became a current issue once again, when over 40 barrels of oil spilled in the field when a shipping pipe was left open. This spill occurred just a few hundred feet from the Kenneth Hahn Park Playground [10].

\subsection{Site Visit}

A site visit was conducted in February 2020 to better understand the site condition and the concern of local communities living adjacent to the Inglewood Oil Field. The main purpose of the investigation was to understand: the boundary between the oil field and the local neighborhoods; the ways and methods of dealing with the excess material produced by the extraction activity; the scale of visual and noise pollution from the pumpjacks; locals' and visitors' own perspective on the existence of the largest urban oil field right in the heart of Los Angeles. The most common feedback regarding the field were complaints about air pollution and its consequences on human health due to the close proximity to the oil field.

Currently, the Inglewood is now reaching the end of its lifetime as the oil in the field is almost depleted [11]. The project proposes Inglewood Oil Field's remediation once its oil extraction comes to an end. Although California used to be one of the biggest oil producers in the U.S., its oil industry has been in decline and therefore Inglewood Oil Field will not be the only field that is reaching its intended life cycle [12] (Figure 2). Earth Choreographer acts as a prototype for the remediation of an increasing number of obsolete oil fields by addressing climate change and depletion of resources.

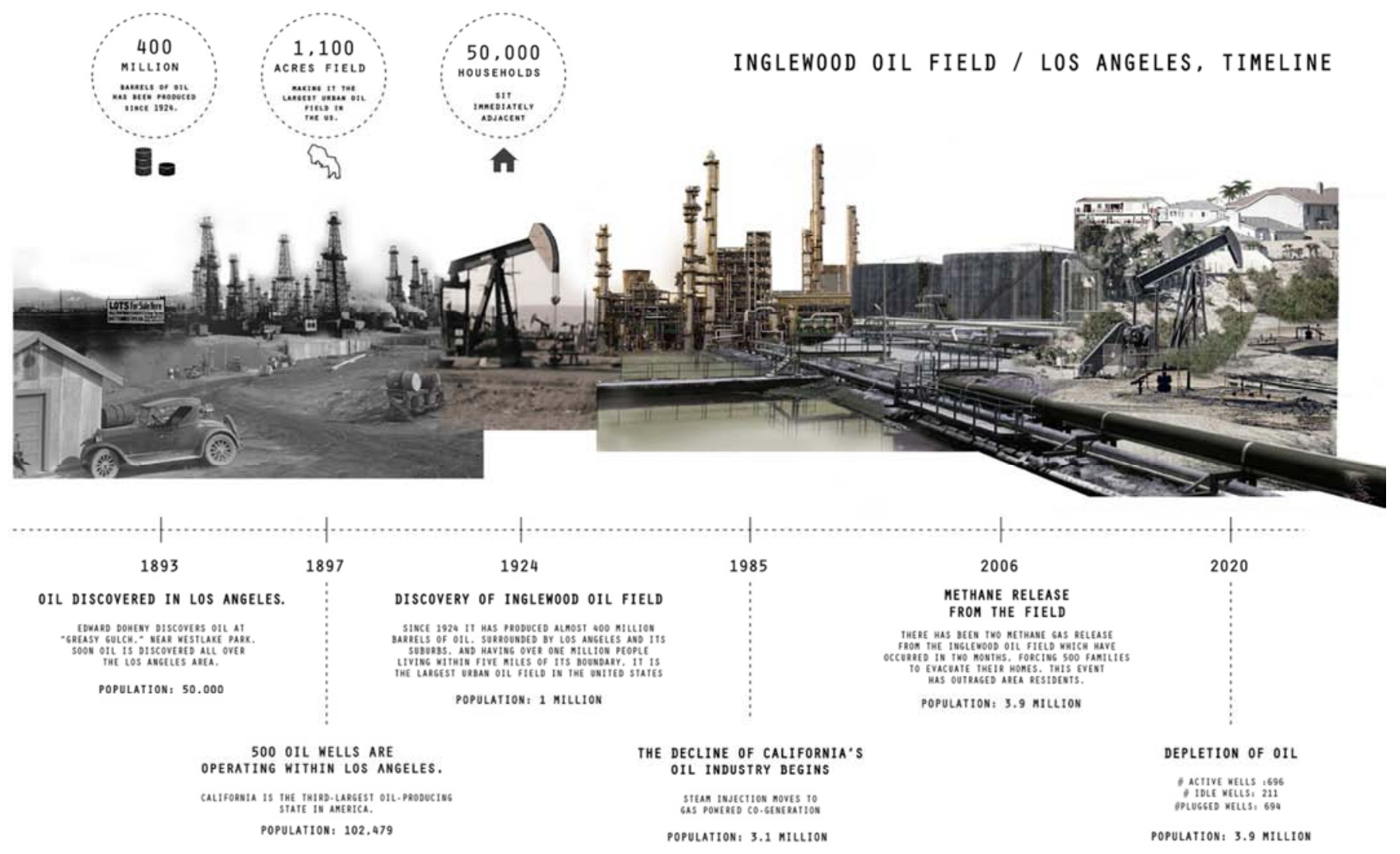

Figure 2. A timeline showing the development of Inglewood Oil Field's Oil Production.

\subsection{The Parameters}

Oil is one of the most valuable matters in the contemporary world and its extraction negatively impacts the environment and landscape. In order to choreograph the remediation of the site, the existing land conditions and materials created by the oil production process were investigated. Firstly, the toxicity and the contamination of the soil were analyzed and located (Figure 3 ). As of 2020, there are a significant number of idle wells on the site that are not yet properly capped [12]. As they might be emitting toxins to the soil [13], a combination of physical, biological, and chemical strategies were deployed in order to decontaminate the soil and plug the well (Figure 4).

With the speed of climate change and depletion of natural resources on Earth, there is an urgent need for higher material and energy efficient practices [14]. The design methodology of this project acknowledges and addresses the finite supply of the earth's resources in terms of both extracted and raw materials. Therefore, Earth Choreographer used already 
extracted soil on the site and converted it into rammed earth which is intended to be the primary construction material. For this purpose, the "cut and fill" method was deployed to directly turn extracted excess soil from the drilling sites of oil wells into rammed earth as construction materials, instead of bringing new soil from elsewhere (Figure 4). As the testing grounds were designed to be built around properly capped oil wells, the project followed certain formal and material architectural strategies in order to avoid problems that might occur due to the close proximity with the existing wells. The speculation started with keeping all of the oil wells and reintroducing them as structural elements that are part of the new infrastructure. By carving around the oil wells and maintaining a safe offset around them, the wells start to act as structural columns with a thick layer of soil around them. By keeping the existing oil wells and bringing them into the project as functional elements is one of the key architectural strategies deployed in the testing grounds.

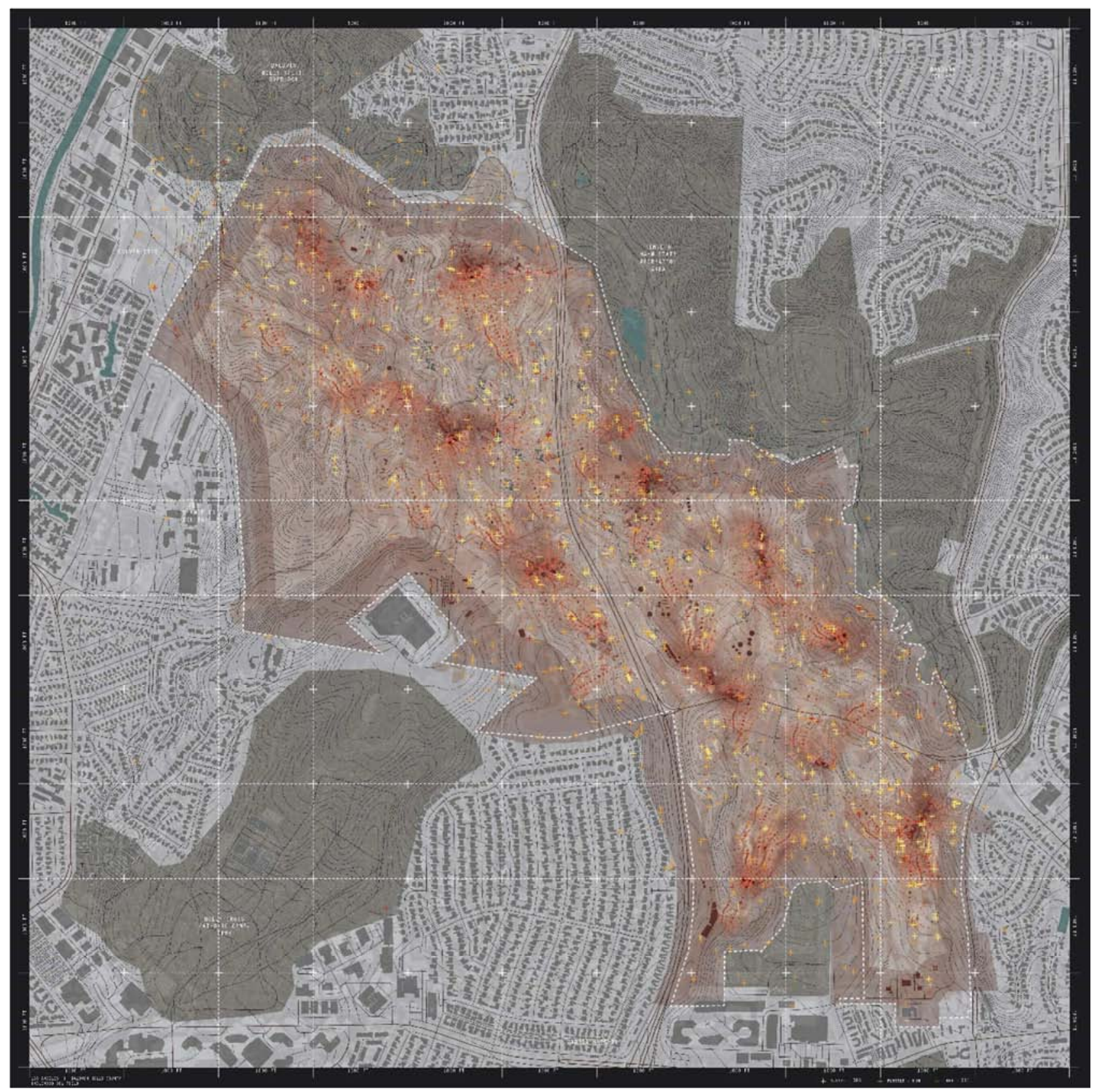

Figure 3. Toxicity Map of Inglewood Oil Field. 


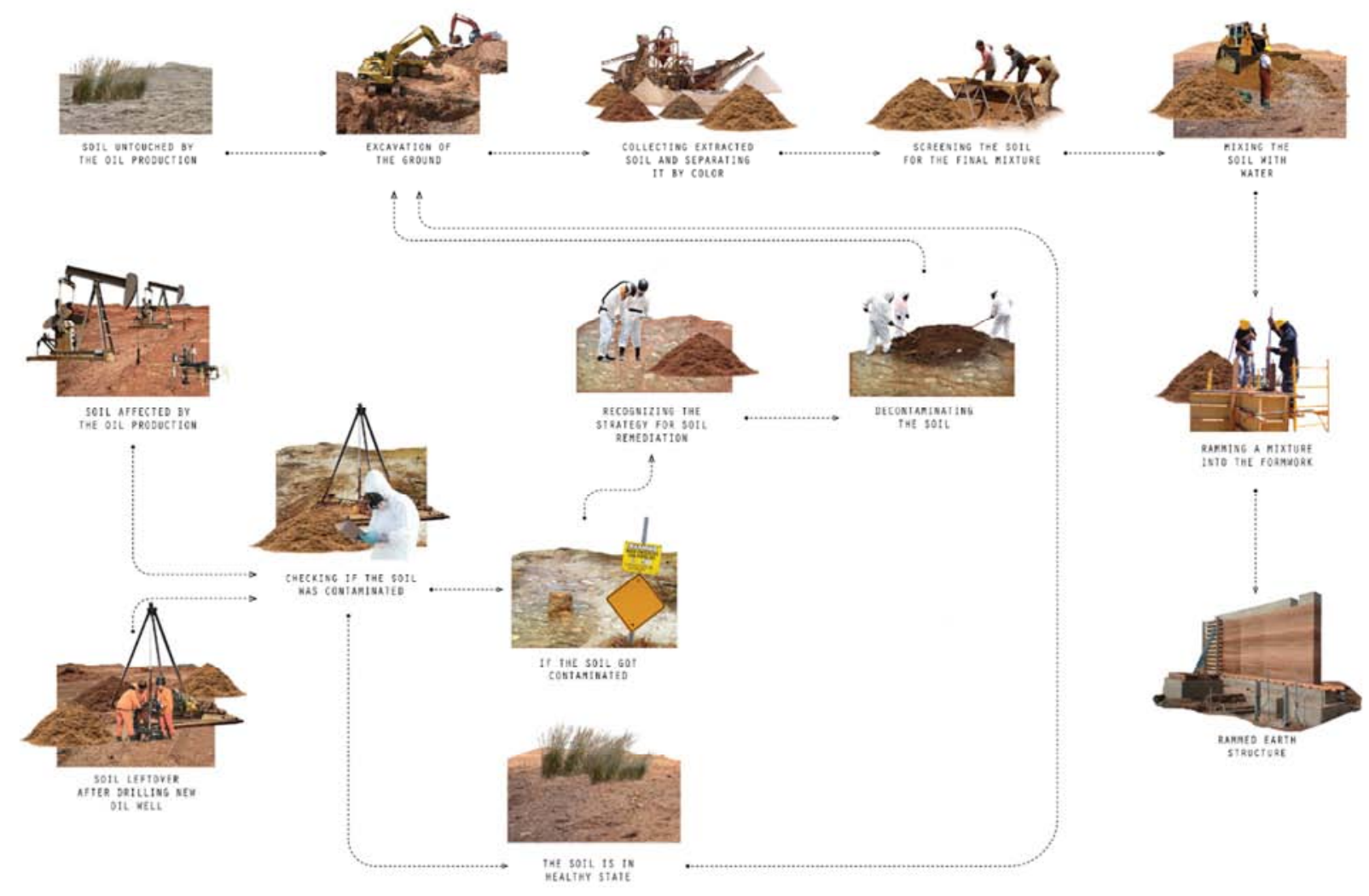

Figure 4. Soil remediation strategy and production methods.

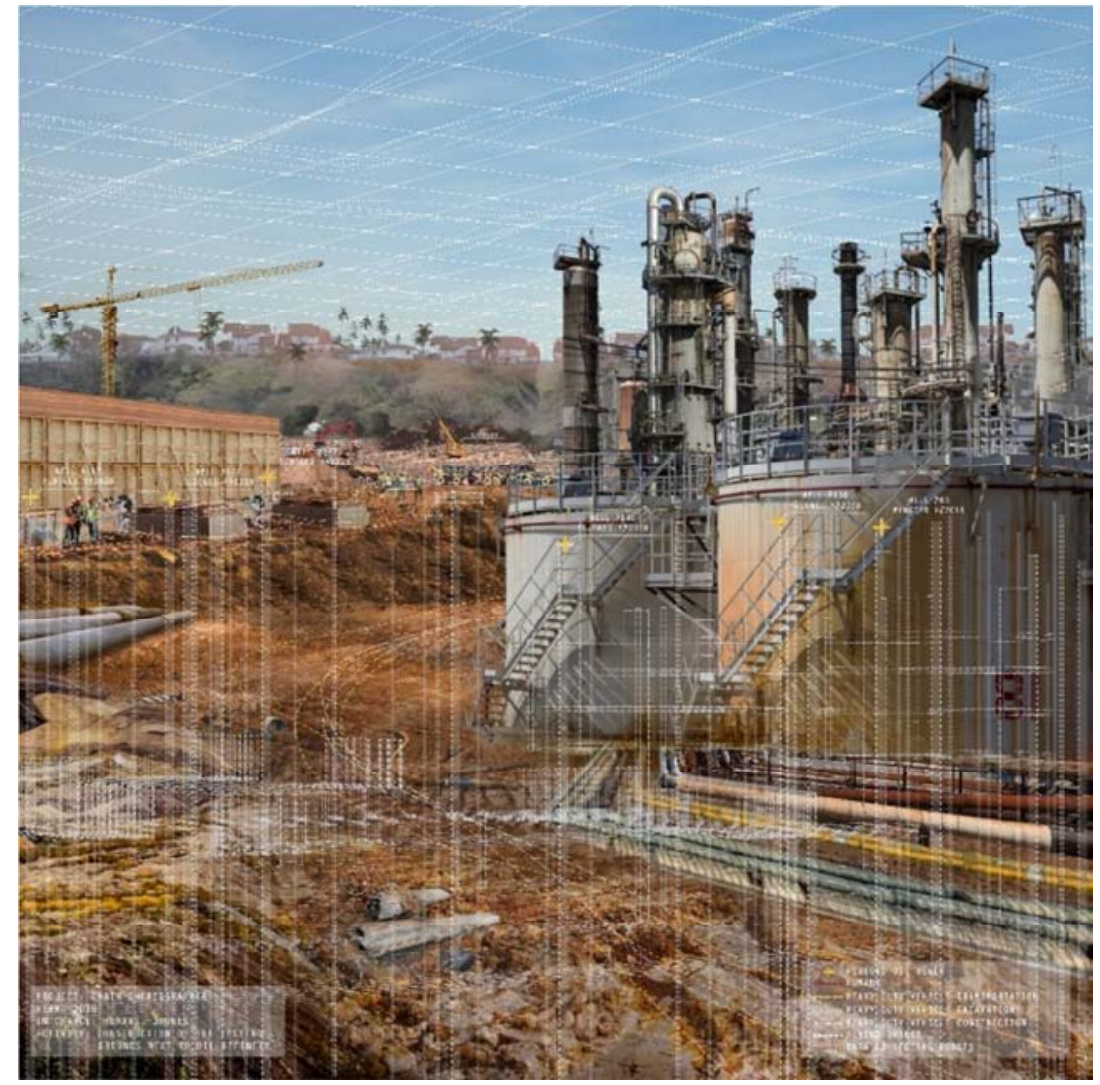

Figure 5. Projection: Year 2030, Existing Oil Infrastructure. 
After analyzing the existing land conditions and determining the priorities while working with the existing landscape, it was concluded that the project should be flexible to adapt to the existing site conditions while responding to climate change and depletion of resources. The project is intended to be an experimental testing ground targeted for future technology institutes and companies such as NASA, Tesla, and Autodesk which work on new technologies as substitutes for fossil fuels and other resources in depletion (Figure 5). The testing ground will be designed to include various programs for these companies, such as makerspaces for fabrication and mock-ups, and simulation labs for air mobility. Their scales and forms will vary depending on the type of space the companies need, and follow the existing topography which has been already altered and traced by the oil production industry, giving tribute to the original landscape and its alterations.

\subsection{The Choreography}

This project proposes a constant reconfiguration of the oil field's landscape which will be reclaimed parcel by parcel as it becomes available, and continue growing and extending in phases over the coming decades. The phases for construction were determined by analyzing the spatial distribution of idle and plugged wells located in the Inglewood Oil Field. The construction begins where the concentration of the idle and capped wells are highest. As the ground is being remediated, precautions are taken to avoid possible accidents that might occur due to close contact with the wells. A radius of $100 \mathrm{ft}$ of unbuildable area is given to ensure safety around the active wells. Therefore, Earth Choreographer exemplifies a temporal-situational design methodology to simulate a kinetic response to obsolete sites, which presents the ideas of continuous reformatting through permanent construction, reconfiguration, and deterritorialization of the ground by human and non-human agencies. The proposed choreography of the site was shown as frames picked from certain times and locations. Layers of lines in each frame represent the topographic, geographic, and temporal mechanical information. With each phase new lines are introduced to represent the new actors starting to play out in this process. Starting in 2025, the speculation for choreographing the earth will begin from the most populated areas of capped wells, farthest from the active ones (Figure 6).

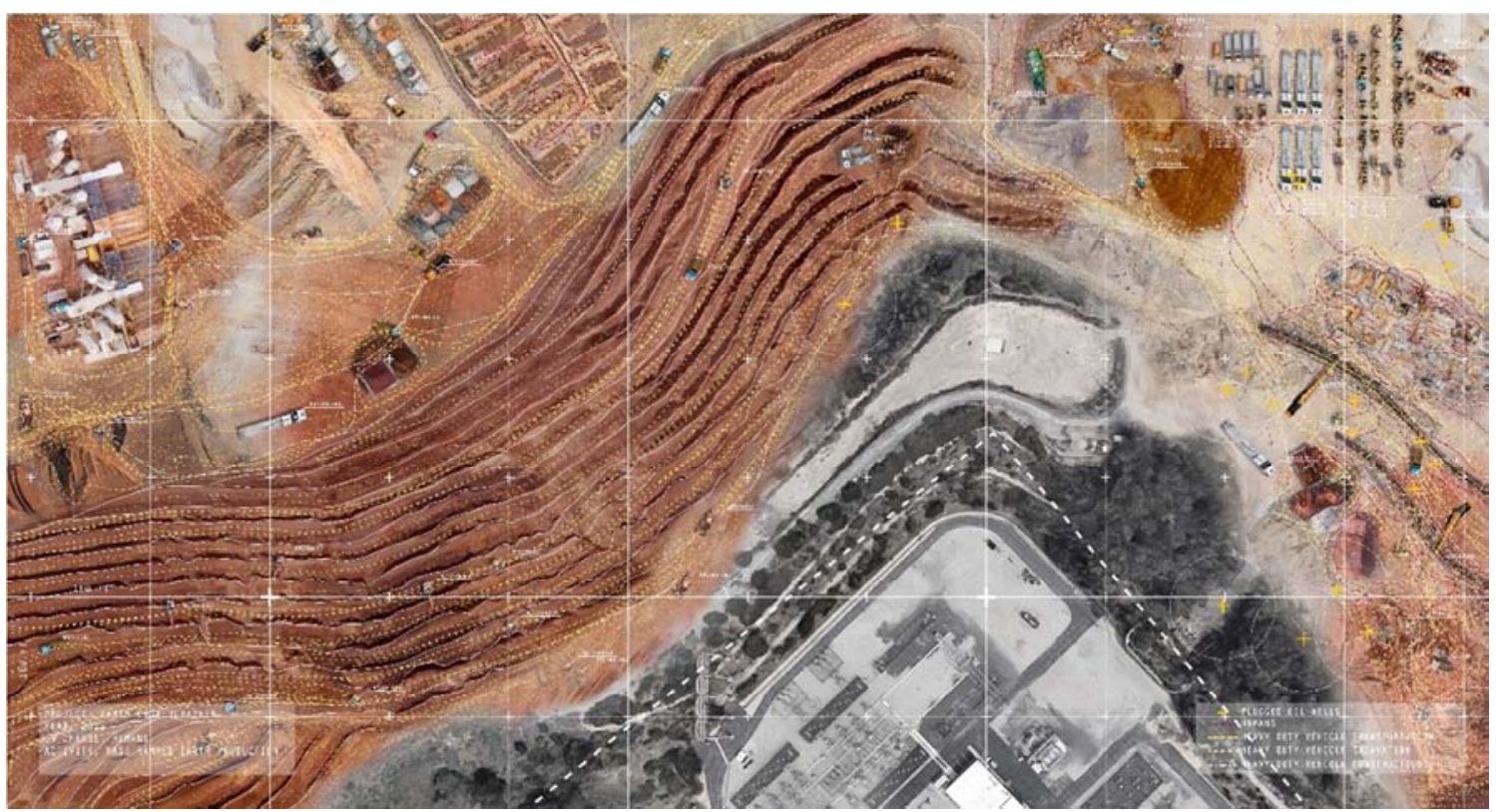

Figure 6. Projection: Year 2030, Progress.

In 2030 , the focus will be relocated to the testing ground close to the existing oil refinery. Although the whole site will be reclaimed, some energy infrastructures for oil production will remain untouched even after they reach the end of their intended life cycle. By suggesting such a remediation strategy, the juxtaposition between the past and the future was emphasized. This was intended to reveal the traces left by obsolete oil infrastructures on the site, arguing that reclamation of the site can be achieved through radical technological juxtapositions without having to be nostalgic. As the oil field is permanently choreographed for its changing occupiers, a variety of robots, drones, and machines will contribute to this process. Both human and non-human actors will work on the site. The actors are choreographed according to the specific tasks they are assigned to, working collaboratively towards constructing the testing ground.

As the focus moves to 2040, the site will be a juxtaposition of the existing recreational park and the productive landscape (Figure 7). A more sustainable energy production facility adjacent to the existing oil infrastructure is proposed, creating a tension between old and new energy production facilities. Above the ground, there is the juxtaposition between the active recreational park and the heavy industrial construction site. This leads to further investigation about 
how to deal with the boundary of public active spaces in close proximity to construction sites and how to sustain a boundary between human and non-human actors (Figure 8). The ground will become the medium for negotiating the energy production above and below the ground. Above, solar energy will be harnessed, and electric power will be generated by the kinetic energy of the stationary bikes in a gym, while below the traces of the obsolete oil infrastructure can be observed. These traces of past and future energy sources will collide and entangle at the surface of the Earth. This collision is exposed by revealing invisible infrastructure through the graphic representation used throughout this project.

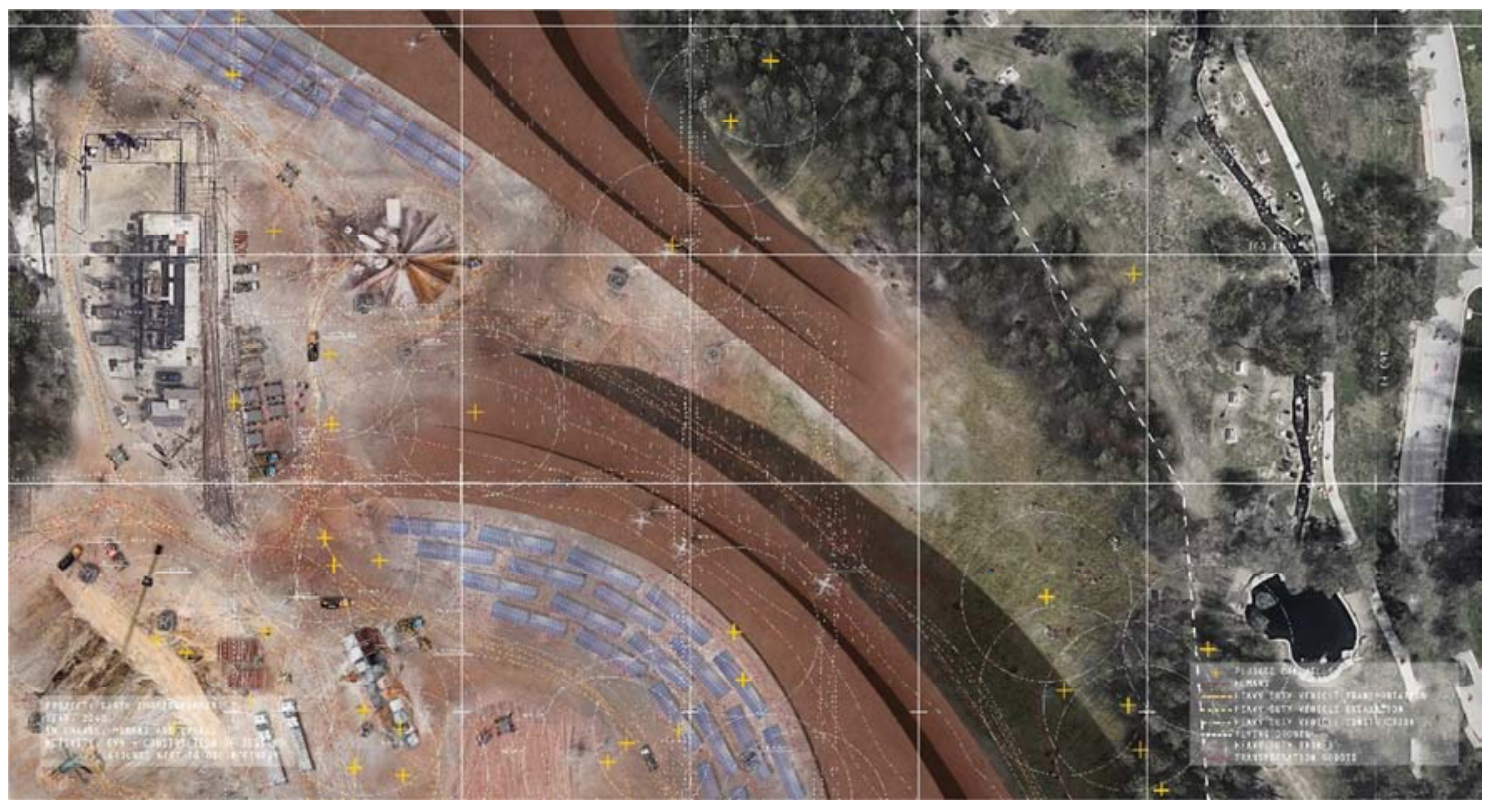

Figure 7. Projection: Year 2040, Boundary with the city.

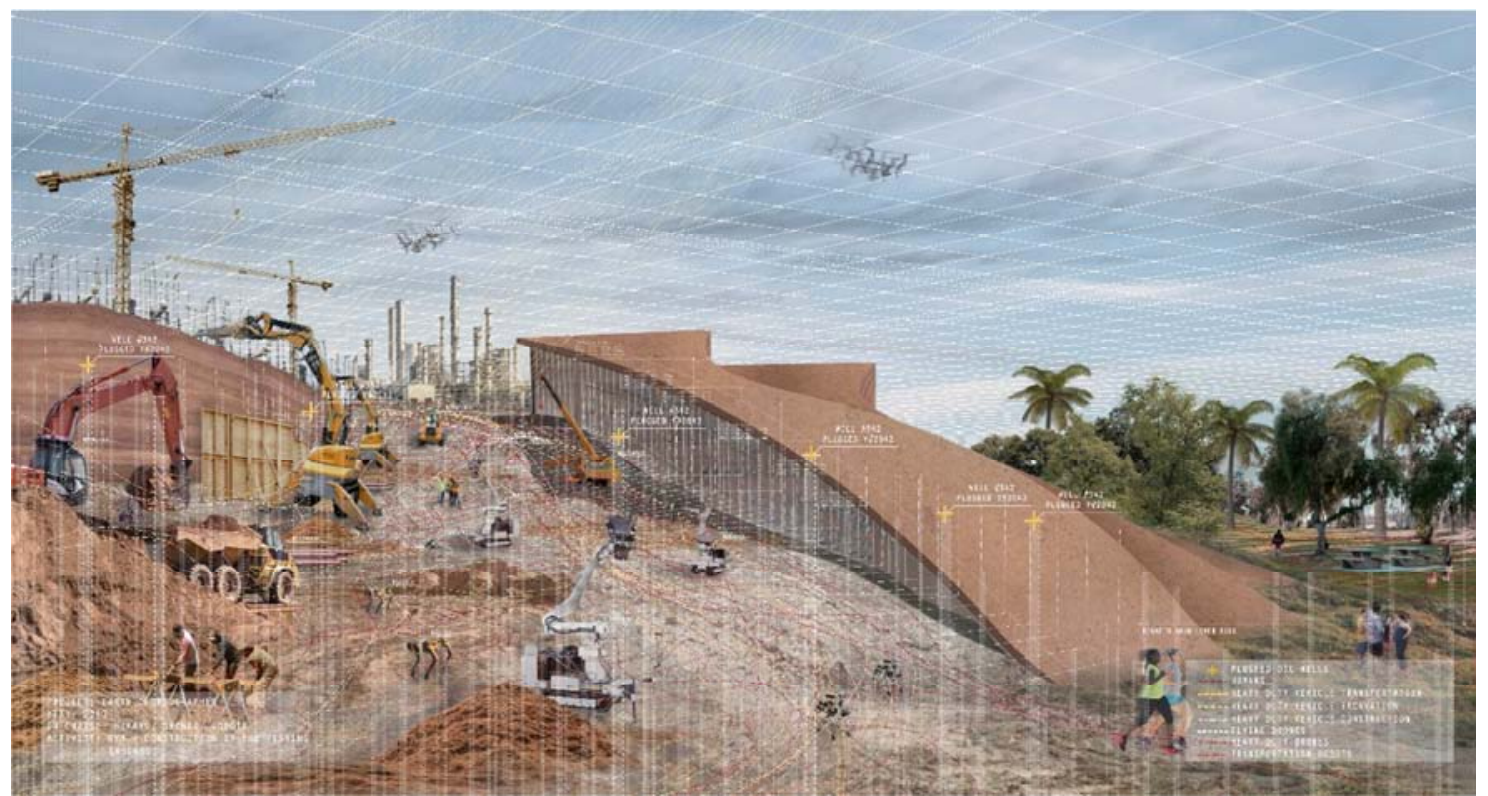

Figure 8. Projection: Year 2040, Construction Progress.

By the year of 2060, Earth Choreographer expects to have fewer people involved in the construction field (Figure 9). The traditional process of rammed earth construction includes repetitive pressurizing of grained earth and it requires a lot of human labor. With the evolving robotic and AI technologies, there will be a shift from human labor to robotics in the construction industry. Most of the human labor will be shifted towards maintaining drones and robots which will be programmed to work in teams to build structures using rammed earth. [15] This shift can address the scarcity of human labors in this project and in the construction industry, showing how new relationships and interactions between human and non-human will be choreographed in the construction site (Figure 10). 


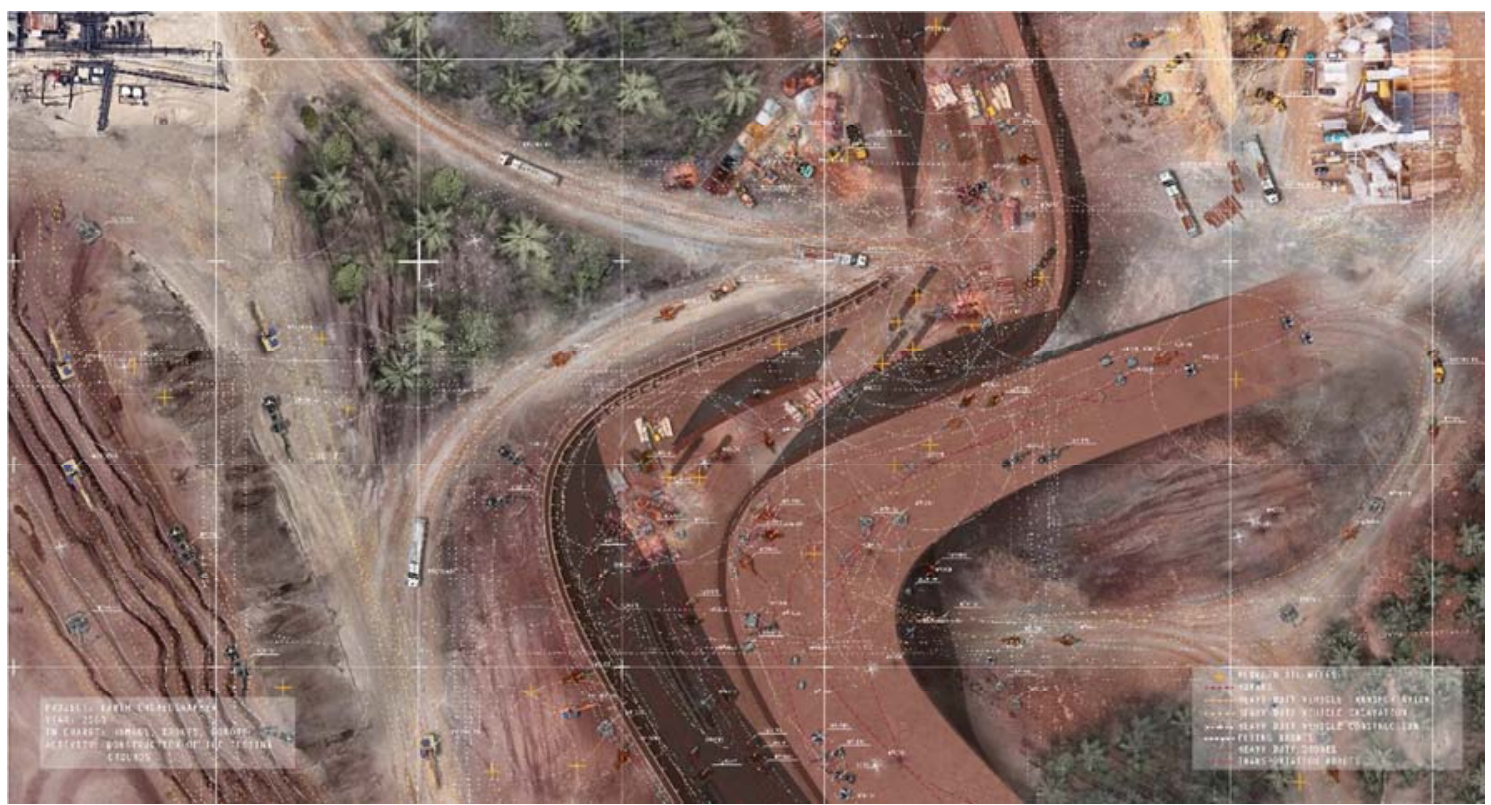

Figure 9. Projection: Year 2060, Top View.

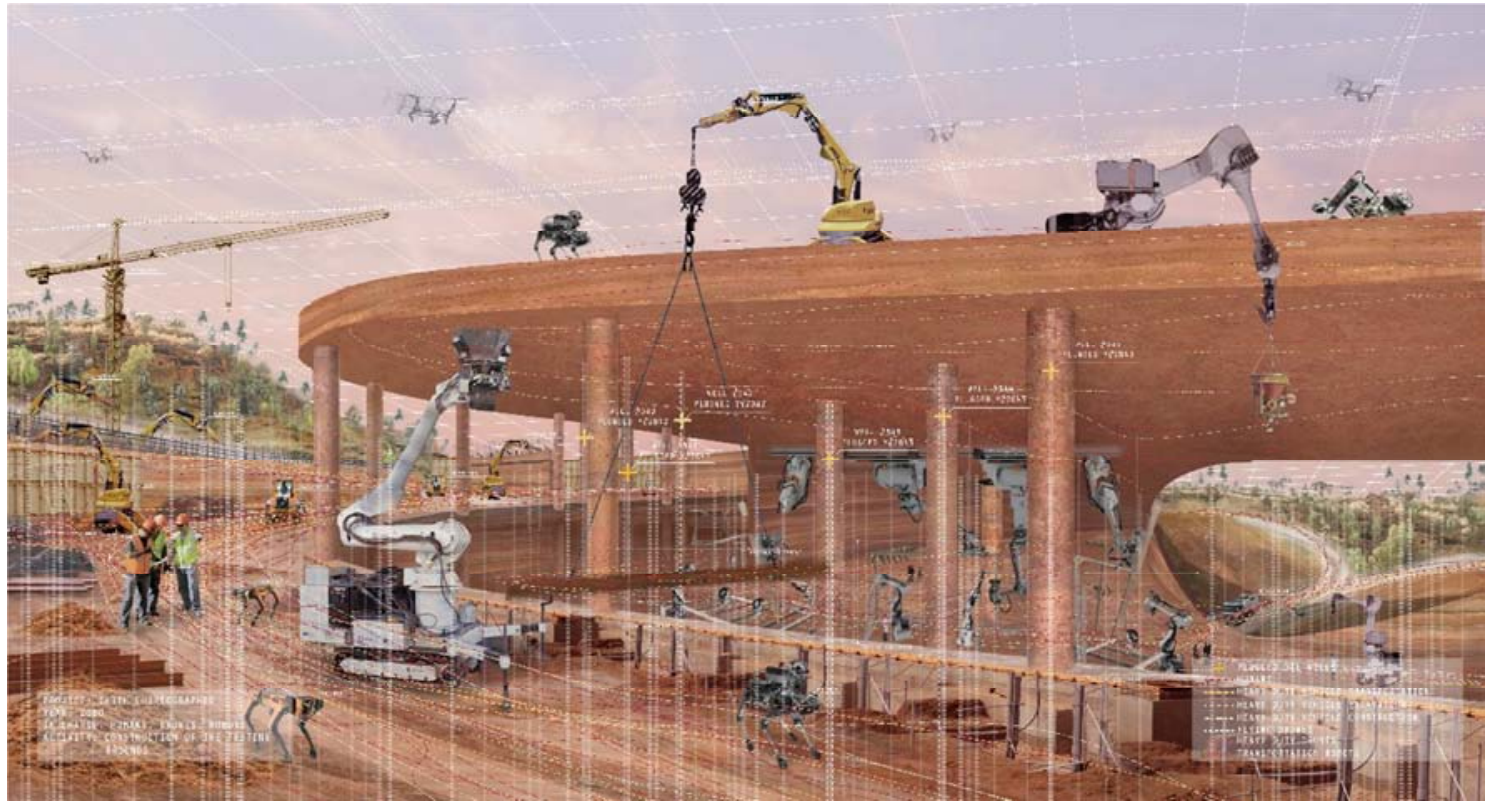

Figure 10. Projection: Year 2060, Perspective.

In 2080, the focus will be shifted to the area adjacent to the city fabric, where the building form is designed to allow the testing ground to be partially exposed to the public. In certain areas, the activity and research done by the technology companies at the testing grounds will be visible to the public. This allows their work to be transparent to a certain extent and allows the community living around Inglewood Oil Field to be familiarized with the developments occurring in the testing grounds.

\subsection{The Graphic Approach}

A notable influence to the graphic approach of Earth Choreographer has been the technique used by the architecture office Design Earth, a collaborative practice led by El Hadi Jazairy and Rania Ghosn. "After Oil”, a speculative project by the office, which imagines the world after the depletion of oil and comments on possible developments of landscapes and geographies influenced the way Earth Choreographer's approach at visualizing the invisible infrastructure of the oil extraction and its consequences on the environment [16].

\subsection{The Prototype}

By 1930, California was producing nearly one quarter of the world's oil output and its population had grown to 1.2 million [17]. In the coming decades that followed, many wells closed but even more opened, surrounded by urban and 
suburban growth. However, California's oil has fallen nearly $60 \%$ from its peak in 1985, in part because the state's deposits of heavy crude can't compete with the rest of the cheaper natural gas. An extensive observation of Los Angeles and its growing oil activity was described in 1971 by architectural critic Reyner Banham. In his book "Los Angeles: The Architecture of Four Ecologies" where he categorized the Los Angeles experience into four ecological models, he described the oil activity in Los Angeles as "Venice, intended to be the most stylish of the lot, was overrun by oil drilling and is now a long uncertain strip of frame houses of varying ages, vacant lots, oil-pumps, and sad gravel scrub" [18].

Although Los Angeles remains as the largest urban oil field in the US, currently its oil industry is in decline which will ultimately result in an abundance of obsolete sites [12]. Earth Choreographer is meant to be a prototype for those sites by exemplifying new ways of inhabiting obsolete landscapes of the future (Figure 11). This prototype implements some elements from Stan Allen's identification of the new ecology alongside with future technology [19]. Earth Choreographer embodies Allen's philosophy of "what things can do" rather than "what they look like" and it is showcased through continuous reformatting and reconfiguration of the testing grounds architecture and oil field landscape.

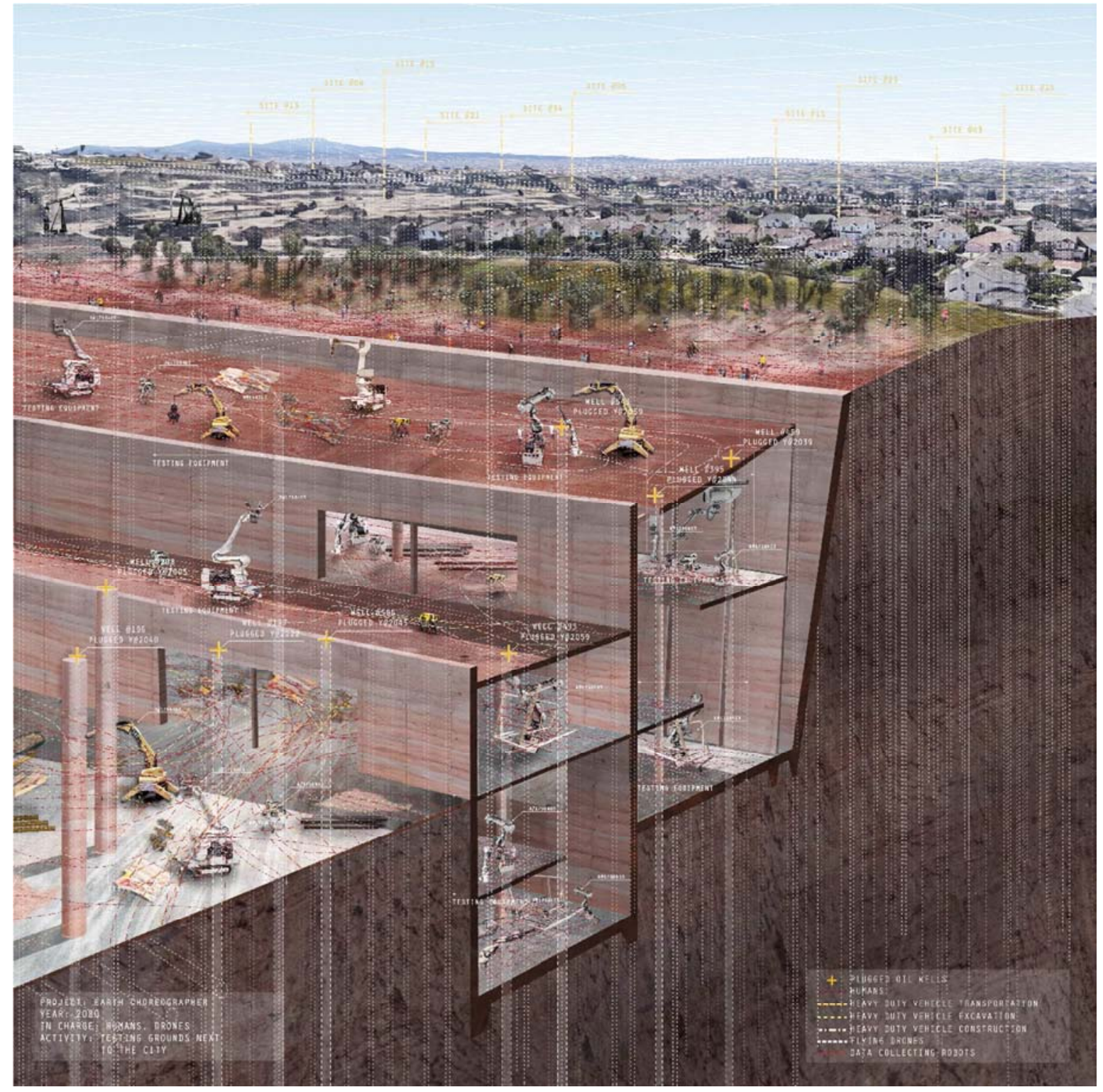

Figure 11. Projection: Year 2080, City Fabric.

Earth Choreographer is heavily influenced by a dynamic design methodology and acts as a prototype by constantly evolving and changing over time based on the needs and interests of its occupiers. By emphasizing a temporalsituational design methodology, it seeks to bring a kinetic response to obsolete sites, providing a pivotal speculation for radically remediating and reprogramming obsolete landscapes of the future. 


\section{Conclusion}

This project aims to raise more questions than it answers about choreography and designing processes. Questions of method and how to design under existing material conditions are asked recognizing that there will always be obsolete technology, obsolete energy production, and obsolete objects throughout the landscape. Hence, it establishes a design process that recognizes the ruination of the ground, landscape and welcomes the problematic and inconsistent connections this brings in its design methodology. It's design process applies plasticity to the program and the site, creating ample room for malleability which enables it to perpetually adapt to changing needs over the decades. Earth Choreographer, thus, becomes an approach of temporalizing the design execution of the design, exploring the concept of obsolescence all the way through to a design method.

The next steps in the research include analyzing how testing grounds can be developed for the use of technology companies that work on sustainable design. This analysis may include getting in communication with prospective occupant companies and considering the specific needs and recommendations such companies could provide. The goal will be to address the ways in which the testing grounds can be used most efficiently for the changing needs of the occupiers. Another consideration is to have a clear understanding of the structural potential of existing oil wells located on site and how the prototype can be implemented on other sites.

\section{Acknowledgements}

The publication of this project became possible thanks to Landscape Architectural Frontier (LAF). LAF contributors: edited by Wang Yinyu, image captions translated to Chinese by Li Huiyan and Wang Yinyu.

Sincerest gratitude to our thesis advisors at Syracuse University School of Architecture Julie May Larsen, Sinead McNamara and Britt Eversole.

\section{References}

[1] Ritchie, Hannah, and Max Roser. " $\mathrm{CO}_{2}$ Emissions by Fuel." Our World in Data.

[2] McGlashen, A. (2020, April 14). Oil Market Woes Raise Concerns That More Wells Will Be "Orphaned".

[3] McKenna, J. (2018, December 21). Abandoned Mines Could Become the Farms of the Future.
[4] Brock, Andrea, and Alexander Dunlap. "Normalising Corporate Counterinsurgency: Engineering Consent, Managing Resistance and Greening Destruction around the Hambach Coal Mine and Beyond." Political Geography. Pergamon, October 12, 2017.

[5] Wilkes, William and Parkin, Brian. "A Coal Mine Is Devouring a 12,000-Year-Old Forest" Bloomberg December 3, 2018.

[6] 6 Centre, UNESCO World Heritage. "Zollverein Coal Mine Industrial Complex in Essen." UNESCO World Heritage Centre.

[7] "History of Inglewood Oil Field." Inglewood Oil Field, October 22, 2020.

[8] "Inglewood, CA Demographic Data." Neighborhood Scout.

[9] Jill E. Johnston, Esther Lim, Hannah Roh, "Impact of upstream oil extraction and environmental public health: A review of the evidence", Science of The Total Environment, Volume 657, 2019, Pages 187-199.

[10] Oil Spill at Inglewood Oil Field Sends Over 1,600 Gallons Flowing Near Communities. Sierra Club. (2021, April 7).

[11] Norimitsu, O. (2014, July 7). A California Oil Field Yields Another Prized Commodity.

[12] Olalde, M., \& Menezes, R. (2020, February 6). The Toxic Legacy of Old Oil Wells: California's Multibillion-Dollar Problem.

[13] E. Allison and B. Mandler. "Petroleum and the Environment. Abandoned Wells: What happens to oil and gas wells when they are no longer productive?", Part 7/24 for AGI, 2018.

[14] Bringezu, S. "Toward Science-Based and Knowledge-Based Targets for Global Sustainable Resource Use”. MDPI. (2019, August 6).

[15] Markoff, J. (2012, August 18). Skilled Work, Without the Worker.

[16] Ghosn, R., \& Jazairy, E. H. (2019). Geostories: Another Architecture for the Environment. Actar Publishers.

[17] Taylor, A. (2014, August 26). The Urban Oil Fields of Los Angeles. The Atlantic.

[18] Banham, R. (1990). Los Angeles: the Architecture of Four Ecologies. Penguin.

[19] Reed, Chris. (2016). The Agency of Ecology. Essay. In Ecological Urbanism. Zu rich, Switzerland: Lars $\mathrm{Mu}$ ller Publishers. 